\title{
Editorial
}

\section{The importance of depression following myocardial infarction}

Depressive disorder, as defined by standardised research criteria, is recorded in $13-19 \%$ of patients at the time of myocardial infarction (MI). ${ }^{1-7}$ The disorder is important in MI patients because depression is associated with several adverse outcomes: increased mortality, ${ }^{15-7}$ angina, ${ }^{2}$ arrhythmias, ${ }^{268}$ rehospitalisation, prolonged disability, and continued smoking.

\section{Increased mortality}

There is increasing evidence that depressed myocardial infarction patients have an increased mortality rate $^{1-6}$; this effect appears to be independent of the severity of MI and is impressive. In the most quoted study, examining six month mortality, patients with major depression had an increased mortality rate: after adjusting for other factors (previous MI, age and Killip class) the adjusted hazard ratio was 3.3 (95\% confidence intervals (CI) 1.96 to 4.68). ${ }^{1}$ At 18 months' follow up the adjusted odds ratio was 6.6 for patients who had depressive symptoms shortly after the MI. ${ }^{5}$ If these results were replicated in the UK, the increased mortality associated with depressive disorder would represent approximately 20000 patients per annum.

\section{Severity and duration of depression}

The association between depression and increased mortality is derived from studies including small numbers of depressed patients, and the studies are not entirely consistent. A number of methodological difficulties must be considered, namely that studies have varied in their measures of depression, the inclusion rates of patients and the proportions of men and women (table 1). ${ }^{2}{ }^{6-12}$ All studies agree that depression in $\mathrm{MI}$ is independent of the severity of the infarction.

\section{Diagnosis}

Diagnosis of depressive disorder according to research criteria requires consistent symptoms over two weeks. It is not clear whether depressive symptoms that have only been present for 7-10 days after an MI should be regarded as depressive disorder. In addition, it appears that the presence of a few depressive symptoms (a Beck depression inventory score $>10$ ) immediately after the infarct accurately predicts mortality at 18 months. ${ }^{5}$ It is not clear why mild depression should be predictive of increased mortality. It is known that chronic depressive disorder (that is, occurs many months before the $\mathrm{MI}$ ) is associated with more severe depression, more social problems, and reduced chance of stopping smoking after an $\mathrm{MI} .{ }^{13}{ }^{14}$

\section{Social stress and depression}

Two studies emphasised the greatest effect of depression on mortality among women, especially those recently divorced. ${ }^{10}{ }^{15}$ These findings concur with previous studies that show that social stress and social isolation are linked to an increased risk of MI and subsequent increased mortality. ${ }^{16-18}$ Lespérance et al reported that low social support was only associated with increased mortality in those who were also depressed. ${ }^{19}$ Denollet and Brutsaert's construct of "type D personality", which appears to be particularly closely related to increased mortality or recurrent MI, consists of depression combined with social inhibition. ${ }^{11}$

\section{Possible mechanisms}

The possible mechanisms linking depression to increased mortality are somewhat speculative at present. Most authors make reference to the increased vulnerability to arrhythmias as a result of a damaged myocardium and the increased sympathetic tone that occurs in depression. ${ }^{20}$ Support for these hypotheses comes from the observations that:

- the increased mortality of the depressed patients in one study was concentrated among those with 10 premature ventricular contractions per hour ${ }^{1}$

- emotional distress is only associated with increased mortality in patients with non-Q wave myocardial infarction

- depressed cardiac patients have an increased heart rate and decreased heart rate variability. ${ }^{821}$

There have been suggestions in the literature that the increased vulnerability to arrhythmias may relate to increased cortisol, increased adrenaline (epinephrine) and noradrenaline (norepinephrine) that occur in depression, but there is little evidence to fully substantiate these ideas.

The other important possibilities are behavioural factors. Depressed subjects may be less likely to adhere to medication regimens, to take exercise, to stop smoking, or to change their diet. The link between depression at the time of $\mathrm{MI}$ and reduced chance of smoking cessation is a compelling reason for cardiologists to identify depression at the time of the infarct. ${ }^{22}$

Table 1 Studies investigating the association between depression and mortality in myocardial infarction patients

\begin{tabular}{|c|c|c|c|c|c|c|}
\hline & $\begin{array}{l}n \text { (\% of MI } \\
\text { patients recruited) }\end{array}$ & Female (\%) & $\begin{array}{l}\text { Definition/ } \\
\% \text { depressed }\end{array}$ & $\begin{array}{l}\text { Duration of } \\
\text { follow up }\end{array}$ & $\begin{array}{l}\text { Deaths in } \\
\text { depressed group (n) }\end{array}$ & $\begin{array}{l}\text { Adjusted } \\
\text { risk ratio }\end{array}$ \\
\hline Frasure Smith ${ }^{1}$ & $222(67)$ & 22 & $\begin{array}{l}\text { MDD } 16 \% \\
\text { BDI }>10,31 \%\end{array}$ & $6 \& 18$ months & $\begin{array}{l}6 / 35,6 \text { months } \\
12 / 68,18 \text { months }\end{array}$ & $\begin{array}{l}3.1 \\
6.64\end{array}$ \\
\hline Ladwig $^{6}$ & $552(70.8)$ & 0 & $\begin{array}{l}\text { Severe } 14.5 \% \\
\text { Moderate } 22 \%\end{array}$ & 6 months & $6 / 80$ & 4.9 \\
\hline Schleifer ${ }^{2}$ & $282(66.5)$ & 38 & MDD, $18 \%$ & 3 months & $1 / 52$ & NS \\
\hline Ahern $^{9}$ & $265(52.7)$ & - & BDI, NA & 1 year & $6 / 13$ & - \\
\hline Stern $^{10}$ & 68 & 19 & Zung, NA & 1 year & $6 / 13$ & \\
\hline Denollet $^{11}$ & 87 & 7 & MBHI, 49\% & $6-10$ years & $11 / 39$ & $\begin{array}{l}\text { OR, } 7.5 \\
\quad \text { (unadjusted) }\end{array}$ \\
\hline Kisley $^{12}$ & 79 (97) & 46 & $\begin{array}{l}\text { MDD, } 14 \% \\
\text { PHD }\end{array}$ & 5 years & $8 / 19$ & PHD OR, 5.06 \\
\hline
\end{tabular}

MDD, Major depressive disorder; BDI, Beck depression inventory; MBHI, Millon behavioral health inventory (pessimism scale); PHD, past history of depression; NA, not available; NS, not significant; OR, odds ratio 


\section{Other adverse outcomes}

Depression has an adverse effect on other outcomes, such as angina and quality of life. This relation is more firmly established than the effects depression has on mortality. All studies indicate that depression is associated with a range of negative outcomes including more rehospitalisation, more reinfarction, angina, emotional instability, domestic social impairment, continued smoking, delayed return to work, and impaired quality of life. ${ }^{23-26}$ One recent study found that depression $(\mathrm{OR}=1.99)$ was second only to history of previous $\mathrm{MI}(\mathrm{OR}=2.31)$ out of a long list of possible predictors of functional limitation of daily activities one year after MI. ${ }^{27}$ These adverse outcomes are of major concern to cardiologists. First, they represent reduced quality of life, which is potentially improved by treatment of the depression. Second, they are responsible for increased health care costs; distressed patients presenting for cardiac rehabilitation incurred nearly four times more health care costs compared with non-distressed patients, through more rehospitalisation and recurrent cardiac events. ${ }^{28}$

\section{Intervention studies}

Several studies have reported that psychosocial interventions reduce mortality in MI patients by up to $40 \%$, possibly because of the beneficial effects on mood. ${ }^{29}$ On the other hand, two recent studies of psychosocial rehabilitation have produced negative results. ${ }^{30}{ }^{31}$ In neither trial, however, was there a significant reduction of depression. In the Welsh trial $^{30}$ the depression scores remained identical in the experimental and control groups- $19 \%$ in each were depressed at the end of the trial. In the Canadian study ${ }^{31}$ the Beck depression inventory score only dropped slightly from 8.1 to 6.9 in the intervention group, similar to the control group (8.4 to 7.6$).^{31}$

To successfully reduce depression, specific psychological treatment might be required. The potential benefits of successful reduction of depression, as we have seen, may be the possible effect on improved mortality and the more certain improvement in quality of life. It is important to note that there is a small group of patients with chronic depression, whose depression does not improve even when they are in a successful rehabilitation programme. ${ }^{32}$ This small group with chronic and persistent depression may be the group responsible for the association between depression and increased deaths and could be targeted in future intervention studies.

\section{Implications for cardiologists}

There is good evidence that detecting and treating depression in MI patients is worthwhile, and successful treatment of depression is believed to improve quality of life and possibly reduce mortality. For patients with chronic depression, an attempt should be made to detect and treat this over and above any treatment of depression in cardiac rehabilitation programmes. It is suggested that routine screening of patients with an appropriate set of clinical questions or a self administered questionnaire to detect depression should be followed, where appropriate, with treatment with antidepressant medication, cognitive therapy, or both. ${ }^{33}$ The selective serorotonin reuptake inhibitors (SSRI) appear to be safe for the treatment of depression in patients with cardiac disease ${ }^{34}$ but further work is needed before this is confirmed. ${ }^{35}$

\section{Conclusion}

It is clear from this review that there are many unanswered questions concerning the relation between depression and increased mortality in MI patients. However, there is clear evidence that approximately one in six MI patients have depression, which is independent of the severity of heart disease and which leads to a poor outcome, including poor quality of life, continued cardiac symptoms, increased heart disease, and, probably, increased mortality. There is some evidence that those who have severe heart disease are at greatest risk of adverse outcome attributable to depression. It is these patients in whom depression is most likely to be missed because both doctor and patient understandably focus their main attention on the heart disease and its treatment. Cardiologists, like other physicians, need to incorporate assessment of mood and treat MI patients with concurrent depression to improve quality of life.

F CREED

Professor of Psychological Medicine,

Rawnsley Building, Manchester Royal Infirmary,

Oxford Road, Manchester M13 9WL, UK

email:francis.creed@man.ac.uk

1 Frasure-Smith N, Lespérance F, Talajic M. Depression following myocardial infarction. Impact on 6 month survival. $\mathscr{f} A M A$ 1993;270:1819-29.

2 Ladwig KH, Röll G, Breithardt G, et al. Post-infarction depression and incomplete recovery 6 months after acute myocardial infarction. Lancet 1994;343:20-3.

3 Schleifer SJ, Macari-Hinson MM, Coyle DA, et al. The nature and course of depression following myocardial infarction. Arch Intern Med 1989;149: 1785-9.

4 Forrester AW, Lipsey JR, Teitelbaum ML, et al. Depression following myocardial infarction. Int $\mathcal{F}$ Psychiatry Med 1992;22:33-46.

5 Frasure-Smith N, Lespérance F, Talajic M. Depression and 18 month prognosis after myocardial infarction. Circulation 1995;91:999-1005.

6 Ladwig KH, Kieser M, Konig J, et al. Affective disorders and survival after acute myocardial infarction: results from the post-infarction late potential acute myocardial infarction: results
study. Eur Heart $\mathcal{F}$ 1991;12:959-64.

7 Silverstone PH. Depression increases mortality and morbidity in acute lifethreatening medical illness. F Psychosom Res 1990;34:651-7.

8 Carney RM, Rich MW, teVelde A, et al. The relationship between heart rate, heart rate variability and depression in patients with coronary artery disease. F Psychosom Res 1988;32:159-64.

9 Ahern DK, Gorkin L, Anderson JL, et al. Biobehavioural variables and mortality or cardiac arrest in the cardiac arrhythmia pilot study (CAPS). Am $\mathcal{f}$ Cardiol 1990;66:59-62.

10 Stern MJ, Pascale L, Ackerman A. Life adjustment post myocardial infarction. Arch Intern Med 1977;137:1680-5.

11 Denollet J, Brutsaert DL. Personality, disease severity and the risk of longterm cardiac events in patients with a decreased ejection fraction after myocardial infarction. Circulation 1998;97:167-73.

12 Kisely S, Guthrie E, Creed FH, et al. Predictors of mortality and morbidity following admission with chest pain. F R Coll Physicians Lond 1997;31:17783.

13 Lloyd GG, Cawley RH. Distress or illness? A study of psychological symptoms after myocardial infarction. Br F Psychiatry 1983;142:120-5.

14 Freedland KE, Carney RM, Lustman PJ, et al. Major depression in coronary artery disease patients with VS without a prior history of depression. Psychosom Med 1992;54:416-21.

15 Powell LH, Shaker LA, Jones BA, et al. Psychosocial predictors of mortality in 83 women with premature acute myocardial infarction. Psychosom Med 1993;55:426-33

16 Ruberman W, Weinblatt E, Goldberg JD, et al. Psychosocial influences on mortality after myocardial infarction. N Engl f Med 1984;311:552-9.

17 Jenkinson CM, Madeley RJ, Mitchell JRA, et al. The influence of psychosocial factors on survival after myocardial infarction. Public Health 1993;107: cial factors

18 Case RB, Moss AJ, Case N, et al. Living alone after myocardial infarction: impact on progress. $\mathcal{F} A M A$ 1992;267:515-19.

19 Lespérance F, Frasure-Smith N, Talajic M. Depression and beyond: affect, arteriosclerosis and death [abstract]. European Neuropsychopharmacology 1995;3:219-20.

20 Cameron O. Depression increases post-MI mortality: how? [editorial] Psychosom Med 1996;58:111-12.

21 Krittayaphong R, Cascio WE, Light KC, et al. Heart rate variability in patients with coronary artery disease: differences in patients with higher and lower depression scores. Psychosom Med 1997;59:231-5.

22 Lloyd GG, Cawley RH. Smoking habits after myocardial infarction. $f$ R Coll Physicians Lond 1980;14:224-6.

23 Cay EL, Vetter AP, Dugard P. Return to work after a heart attack. $\mathcal{f}$ PsychoSom RL, Vetter AP, Dugard $1973 ; 17: 231-43$.

24 MÆland JG, Havik OE. Psychological predictors for return to work after a myocardial infarction. F Psychosom Res 1987;31:471-81.

25 Kisley SR, Creed FH, Cotter L. The course of psychiatric disorder associated with non-specific chest pain. F Psychosom Res 1992;36:329-35.

26 Wiklund I, Sanne H, Vedin A, et al. Psychosocial outcome one year after a first myocardial infarction. $\mathcal{F}$ Psychosom Res 1984;28:309-21.

27 Ickovics JR, Viscoli CM, Horwitz RI. Functional recovery after myocardial infarction in men: the independent effects of social class. Ann Intern Med 1997; 127:518-25.

28 Allison TG, Williams DE, Miller TD, et al. Medical and economic costs of psychologic distress in patients with coronary artery disease. Mayo Clin Proc 1995;70:734-42.

29 NHS Centre for Reviews and Dissemination. Cardiac rehabilitation-effective health care. Volume 4, Number 4. York: University of York, 1998.

30 Jones DA, West RR. Psychological rehabilitation after myocardial infarction. Multicentre randomised controlled trial. BMF 1996;313:1517-21. 
31 Frasure-Smith N, Lespérance, Prince RH, et al. Randomised trial of homebased psychosocial nursing intervention for patients recovering from myobased psychosocial nursing intervention fo

32 Lewin B, Robertson IH, Cay EL, et al. Effects of self-help post-myocardialinfarction rehabilitation on psychological adjustment and use of health services. Lancet 1992;339:1036-40.
33 Lespérance F, Frasure-Smith N. Negative emotions and coronary heart disease: getting to the heart of the matter. Lancet 1996;347:414-15.

34 Roose S, Glassman AH, Attia E, et al. Cardiovascular effects of fluoxetine in depressed patients with heart disease. Am F Psychiatry 1998;155:660-5.

35 Glassman AH, Shapiro PA. Depression and the course of coronary artery disease. Am f Psychiatry 1998;155:4-11.

\section{STAMPS IN CARDIOLOGY}

\section{Hypertension}

These four stamps from Pakistan, Lebanon, and Egypt were issued to commemorate and advertise the World Health Day in 1978 when the theme was "Down with high blood pressure". The different countries shared the design of a downwards arrow and styalised heart. The two stamps from Pakistan illustrate one of the important principles when using postage stamps to advertise public health campaigns. The lower value stamp for local postage (20 paisa) has the health message in Urdu. The 2 rupee stamp for higher postal rates such as international postage has the same health message in English allowing both national and international awareness.

M K DAVIES

A HOLLMAN
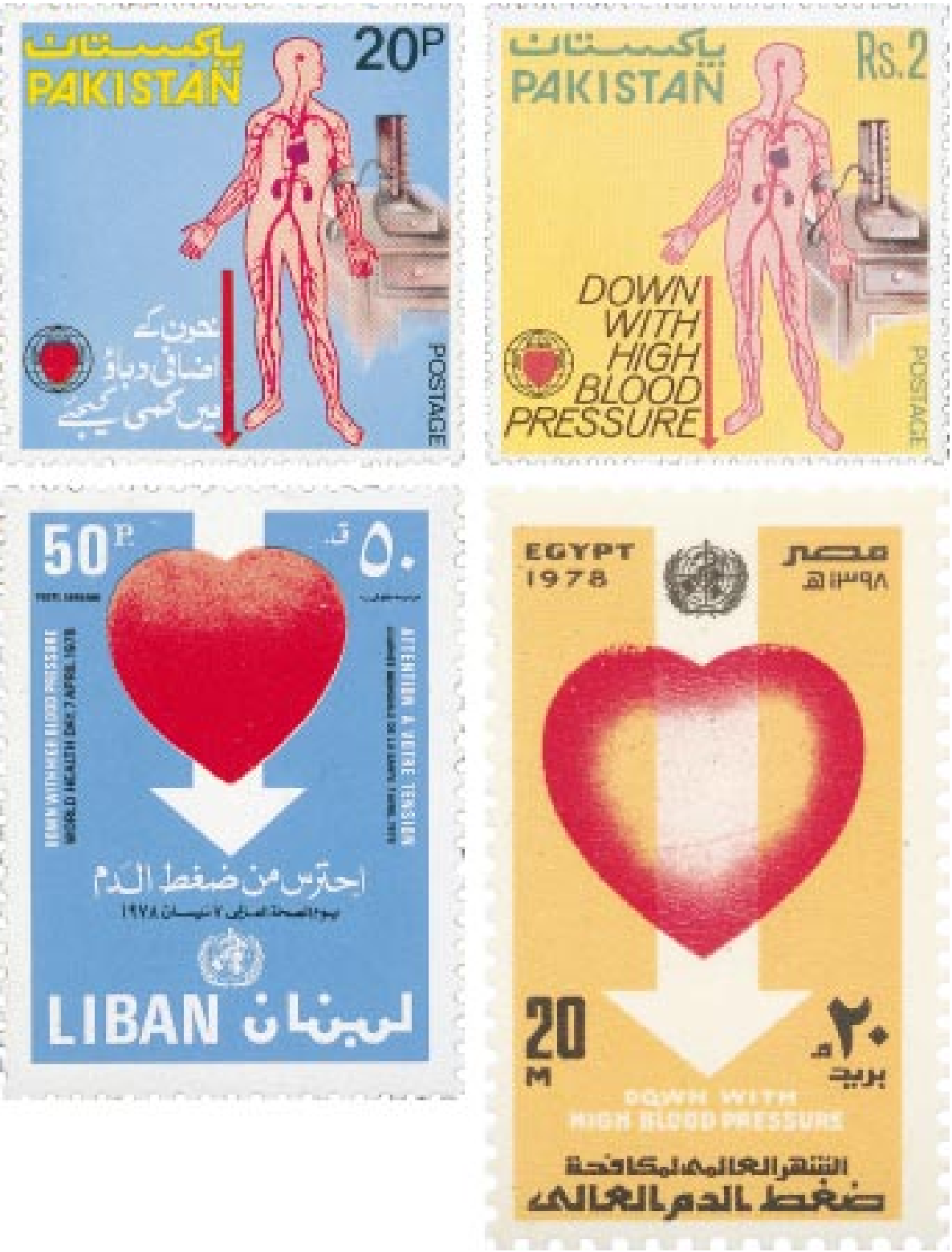